Article

\title{
Synthesis and Characterization of Hybrid Metal Zeolitic Imidazolate Framework Membrane for Efficient $\mathrm{H}_{2} / \mathrm{CO}_{2}$ Gas Separation
}

\author{
Po-Hsueh Chang ${ }^{1}$, Yuan-Tse Lee ${ }^{2}$ and Cheng-Hsiung Peng ${ }^{1, *}$ \\ 1 Department and Institute of Chemical and Materials Engineering, \\ Minghsin University of Science and Technology, Xinxing Road, Hsinchu 30401, Taiwan; \\ pohsueh.chang@gmail.com \\ 2 Department of Materials Science and Engineering, National Chiao Tung University, 1001 University Road, \\ Hsinchu 300, Taiwan; xu3m06yk6@msn.com \\ * Correspondence: must.peng@msa.hinet.net; Tel.: +8863-5593142 (ext. 2119)
}

Received: 19 September 2020; Accepted: 2 November 2020; Published: 6 November 2020

check for updates

\begin{abstract}
In this paper, we propose mixed metal ions in the node of the zeolitic imidazolate framework (ZIF) structure. The hybrid metal ZIF is formed for the gas separation of hydrogen and carbon dioxide. In the first stage, the nanoparticles were prepared as a coating on a substrate, and acting as secondary growing nuclei. The hybrid metal ZIF structures were characterized by X-ray diffractometry (XRD) and Fourier transform infrared spectroscopy (FTIR). $\mathrm{N}_{2}$ adsorption-desorption isotherms determined surface area, and scanning electron microscopy (SEM) was used to observe the microstructure and surface morphology. The hybrid metal ZIF-8-67 powder had the largest surface area $\left(1260.40 \mathrm{~m}^{2} \mathrm{~g}^{-1}\right)$, and the nanoparticles $(100 \mathrm{~nm})$ could be fully dense-coated on the substrate to benefit the subsequent membrane growth. In the second stage, we prepared the hybrid metal ZIF-8-67 membrane on the pre-seeding substrate with mixed metal nanoparticles of cobalt and zinc, by the microwave hydrothermal method. Cobalt ions were identified in the tetrahedral coordination through UV-Vis, and the membrane structure and morphology were determined by XRD and SEM. Finally, a gas permeation analyzer (GPA) was used to determine the gas separation performance of the hybrid metal ZIF-8-67 membrane. We successfully introduced zinc ions and cobalt ions into the ZIF structure, where cobalt had a strong interaction with $\mathrm{CO}_{2}$. Therefore, GPA analysis showed an excellent $\mathrm{H}_{2} / \mathrm{CO}_{2}$ separation factor due to lower $\mathrm{CO}_{2}$ permeability. The $\mathrm{CO}_{2}$ permeance was $\sim 0.65 \times 10^{-8} \mathrm{~mol} \mathrm{~m}^{-2} \mathrm{~s}^{-1} \mathrm{~Pa}^{-1}$, and the separation factors for $\mathrm{H}_{2} / \mathrm{CO}_{2}$ and $\mathrm{H}_{2} / \mathrm{N}_{2}$ were 9.2 and 2.9 , respectively. Our results demonstrate that the hybrid metal ZIF-8-67 membrane has a superior $\mathrm{H}_{2} / \mathrm{CO}_{2}$ separation factor, which can be attributed to its very high specific surface area and structure. Based on the above, hybrid metal ZIF-8-67 membranes are expected to be applied in hydrogen or carbon dioxide gas separation and purification.
\end{abstract}

Keywords: zeolitic imidazolate framework; ZIF-8-67 membranes; gas separation; separation factor; permeance

\section{Introduction}

Zeolitic imidazolate frameworks (ZIFs) are members of a new class of hybrid organic-inorganic materials, called metal-organic frameworks (MOFs), which have relatively regular pores and significant advantages: in a higher specific surface area, ranging from micropores to mesopores; designable structure characteristics, including the skeleton, pore shape, pore size, and surface chemical properties [1]. ZIFs have ordered porous structures with hybrid frameworks, which consist of inorganic metal ions or metal clusters coordinated with organic imidazolate ligands [2,3]. Both the versatility and 
designability of the organic ligands, and the directionality of the metal ion, offer not only conventional adsorptive properties, such as storage, separation, and catalysis, but also other physical/chemical functions integrated into the frameworks. In addition, they have a highly flexible structure, including pore size and surface properties that can be rationally designed. The material's structural properties have relatively high thermal stability and physical-chemical stability, which makes them appear as excellent candidates for superior-performance gas separation or purification membranes [2]. The structural composition of ZIFs consists of metal atoms (such as $\mathrm{Zn}$ and $\mathrm{Co}$ ) regularly connected with ditopic imidazolate (Im), or functionalized $\mathrm{Im}$, and $\mathrm{N}$ atoms to form neutral frameworks [4].

To date, of the practical applications of gas separation that have been undertaken [5], and with energy efficiency as the primary consideration, membrane-based separation has advantages compared with pressure swing adsorption and cryogenic distillation. Although several MOF membranes have been synthesized by different methods [6], ZIF membranes still have better gas separation performance [7]; however, their structure and function control remains a challenge. Bux et al. successfully prepared a zeolitic imidazole framework-8 (ZIF-8) membrane with molecular sieving properties using microwave-assisted synthesis. In addition, the results showed that the ZIF- 8 membrane achieved a balance between permeability and selectivity [8]. Recently, Pan et al. prepared a membrane with excellent gas separation performance, combining the ZIF-8 membrane on the surface of hollow yttrium-stabilized zirconia (YSZ) fiber by an environmentally friendly seeded growth method [9]. On the other hand, ZIF-67 is one of the most studied materials, and its microporous framework structure is formed by cobalt cations linked 2-methylimidazolate anions [10]. ZIF-67 has remarkable chemical stability and a large surface area $\left(>1000 \mathrm{~m}^{2} / \mathrm{g}\right)$, and is widely used for the selective separation of $\mathrm{CO}_{2}, \mathrm{O}_{2}, \mathrm{~N}_{2}$, and $\mathrm{CH}_{4}$ [11]. However, due to the microporous nature of ZIF-67, which has a small pore size $(1.16 \sim 0.34 \mathrm{~nm})$, the adsorption properties are obstructed by the slow diffusion kinetics [12,13]. This phenomenon severely limits the application of ZIF-67 in separation, adsorption, and catalysis. In particular, the problem may become more serious when the size of the adsorbed molecule is similar to or larger than the micropore diameter.

So far, most developed ZIFs have been based on a single metal. Many intrinsic properties of ZIFs, such as thermal stability, chemical resistance, and structural density, depend on the metal composition. Therefore, to effectively and stably configure the composition of mixed metal ZIFs will be an effective method to regulate their essential properties. Each metal can form separated clusters, resulting in a mixture of discrete ZIFs. These add to the difficulty of synthesizing mixed metal ZIFs. The synthesis of mixed metal ZIFs generally uses linkers with free reactive functional groups. However, the functional groups can coordinate with other metals not only pre-synthesis, but also post-synthesis. Few attempts have involved the gas selective embeddedness of the different metals, and included a mixture of metal in the framework's nodes. Cobalt was selected for this study because of its excellent interaction properties with $\mathrm{CO}_{2}$, making the membrane useful for gas separation applications [14,15]. It has been reported that the ligand 2-methylimidazole ( $\mathrm{mIM}$ ) reacting with $\mathrm{Zn}$ or Co salts can be used to prepare ZIF-8 or ZIF-67, respectively.

Previously, the approach commonly used was to design novel materials, chemically modified using functional groups. Some strategies have recently been proposed to tune the properties of MOFs, and control framework porosity and functionality, by mixed-linker synthesis $[16,17]$. Some ZIFs of $\mathrm{Zn}^{2+}$ and $\mathrm{Co}^{2+}$ with mIM (ZIF-8 and ZIF-67) have also been developed, but few studies have been conducted on mixed metal ZIFs synthesis, and studied their properties. Botas et al. [18] reported that they synthesized a framework of $\mathrm{Zn}_{4} \mathrm{O}(\mathrm{bdc})_{3}$, and then replaced $\mathrm{Zn}^{2+}$ with $\mathrm{Co}^{2+}$ through ion replacement. The results showed that the adsorption capacity of $\mathrm{H}_{2}, \mathrm{CO}_{2}$, and $\mathrm{CH}_{4}$ under high pressure was better than samples without $\mathrm{Co}^{2+}$. Zhang et al. [19] prepared mixed-matrix membranes (MMMs) by embedding $\mathrm{Ni}^{2+}$ replaced ZIF- 8 to form $\mathrm{Zn} / \mathrm{Ni}$ based ZIF-8, and then making a polyether block amide polymer, which was applied to $\mathrm{CO}_{2} / \mathrm{N}_{2}$ mixed gas separation. The results showed that the ratio of $10 \% \mathrm{Zn} / \mathrm{Ni}$ based $\mathrm{ZIF}-8$ had the best gas separation capacity, with a $\mathrm{CO}_{2}$ flux of 282 Barrer, and selectivity of 42.7 , for $\mathrm{CO}_{2} / \mathrm{N}_{2}$, respectively. Fan et al. [20] used imidazole, polyimides, and ZIF-8 
to prepare membranes with a high separation performance through an exquisite synthesis method. A gas separation analysis displayed the selectivity of $\mathrm{H}_{2} / \mathrm{CH}_{4}$, which increased with the increase of the ZIF-8 ratio, resulting in a selectivity of 318.3 , while $\mathrm{H}_{2}$ permeability was approximately 72.3 Barrer.

However, the direct synthesis strategy may provide a simpler process for preparing a novel hybrid metal ZIF-8-67 membrane, with highly stable and excellent gas separation of $\mathrm{H}_{2} / \mathrm{CO}_{2}$. This strategy was adopted in this work and can hopefully approach the ideal membrane performance.

We report the synthesis of hybrid metalZIF-8-67 membranes, c-oriented by the microwave hydrothermal method. This study aims to compare the difference in $\mathrm{H}_{2} / \mathrm{CO}_{2}$ gas separation efficiency between single metals (ZIF-8 and ZIF-67) and hybrid metals (ZIF-8-67). In addition, the optimal cobalt content, characterization, and theoretical mechanism of c-oriented crystal growth, dependent on the preparation route, is discussed, which was further observed by scanning electron microscopy (SEM) and X-ray diffraction (XRD) analysis.

\section{Experimental Methods}

\subsection{Synthesis of ZIF-8-67 Nanocrystals}

Synthesis of ZIF-8-67 nanocrystals was undertaken as follows. A 0.5:0.5:16:16 Zn:Co:ligand:TEA of molar ratio $0.366 \mathrm{~g} \mathrm{Zn}\left(\mathrm{NO}_{3}\right)_{2} \cdot 6 \mathrm{H}_{2} \mathrm{O}$ and $0.358 \mathrm{Co}\left(\mathrm{NO}_{3}\right)_{2} \cdot 6 \mathrm{H}_{2} \mathrm{O}$ was dissolved in $50 \mathrm{~mL}$ deionized water (DI water) and was defined as solution A. The mIM of $3.232 \mathrm{~g}$ and $5.49 \mathrm{~mL}$ TEA was stirred in $50 \mathrm{~mL}$ DI water until dissolved, which was defined as B solution. Solution A was added to solution B, and stirred for $10 \mathrm{~min}$. At this time, the liquid quickly changed from transparent to purple. The mixed solution was separated through centrifugation, the supernatant was decanted, and then the sample was collected and dried in the air in a $60^{\circ} \mathrm{C}$ oven for $24 \mathrm{~h}$. Ratio samples of 0.5:0.5:16:4 and 0.5:0.5:4:16 Zn:Co:ligand:TEA were synthesized by half or twice the masses of ligand and TEA, respectively.

\subsection{Synthesis of ZIF-8, ZIF-67, and ZIF-8-67 Hybrid Membrane}

Porous $\alpha$-alumina $\left(\alpha-\mathrm{Al}_{2} \mathrm{O}_{3}\right)$ (Fraunhofer IKTS) with a diameter around $30 \mathrm{~mm}$ and thickness around $1 \mathrm{~mm}$ was selected as the substrate for the membrane growth. The normal pore size is around $160 \mathrm{~nm}$ and the porosity is about $35 \%$. The seeding solution was prepared using $5 \%$ polyethyleneimine (PEI, Aldrich), $4 \%$ sodium bicarbonate (98\%, Aldrich), and $30 \mathrm{~mL}$ deionized water, and then the pre-synthesized ZIF-8, ZIF-67, and ZIF-8-67 nanocrystals were dispersed in the solution. The seeds were uniformly coated on the aluminum oxide substrate by a spin coating method. After spin coating, the discs were immediately dried in the oven at $60^{\circ} \mathrm{C}$ for $24 \mathrm{~h}$. The pretreated support was placed in a microwave autoclave with the secondary growth solutions of $1 \mathrm{mmol} \mathrm{ZnCl} 2$ (98\%, Showa), $1 \mathrm{mmol}$ $\mathrm{Co}\left(\mathrm{NO}_{3}\right)_{2} \cdot 6 \mathrm{H}_{2} \mathrm{O}$ (98\%, Showa), $4 \mathrm{mmol} 2$-methylimidazole (mIM, 97\%, Acros), and $2.7 \mathrm{mmol}$ sodium formate (SF, $99.5 \%$ Aldrich), which were dissolved in methanol $\left(99 \%\right.$, Aldrich) at $100^{\circ} \mathrm{C}$ for $4 \mathrm{~h}$.

\subsection{Characterization}

X-ray diffraction (XRD) patterns were collected by recording $2 \theta$ values ranging from $5^{\circ}$ to $50^{\circ}$ using a Bruker D8 Advance X-ray diffractometer. The samples (ZIF-8, ZIF-67, and ZIF-8-67) were characterized by sorptometry to determine the surface area via nitrogen adsorption at $-196{ }^{\circ} \mathrm{C}(77 \mathrm{~K})$ in a Micromeritics ASAP 2010 system. Prior to measurement, the samples were activated in situ by holding at $150{ }^{\circ} \mathrm{C}$ under a vacuum $(0.13 \mathrm{~Pa})$ for $2 \mathrm{~h}$. However, the surface area data were the average of three measurements taken for each sample. Scanning electron microscopy (SEM) images were obtained from a JEOL JSM-6700F instrument operating at $15 \mathrm{kV}$ and a current of $10 \mu \mathrm{A}$. The particle size distribution was evaluated using DI water as a dispersion medium at room temperature, and the samples were measured through dynamic light scattering (DLS) by a Photal ELS-8000 (OTSUKA Electronics). Thermal gravimetric analysis (TGA) measurements were recorded on a TA Instrument Q500, which was used to analyze thermal properties from 25 to $800{ }^{\circ} \mathrm{C}$ at a rate of $5{ }^{\circ} \mathrm{C} \mathrm{min}^{-1}$ under nitrogen gas. Ultraviolet-visible spectroscopy (UV-Vis) was carried out in a Cary 300 instrument with 
a diffuse reflectance accessory in the wavelength range of 200-1000 nm. Gas permeation analyzer (GPA) data were collected on a Yanaco GTR-11MH, and the apparatus was employed to measure the permeability of the hybrid metal ZIF-8-67 membranes for pure $\mathrm{H}_{2}, \mathrm{CO}_{2}$, and $\mathrm{N}_{2}$. Tests were carried out at different temperature and pressure conditions. The gas permeability was determined by the following equation:

$$
P=\frac{q}{\left(P_{1}-P_{2}\right) \cdot A \cdot t}
$$

where $P$ is the gas permeability $\left(\mathrm{cm}^{3}(\mathrm{STP}) / \mathrm{cm}^{2} \mathrm{~s} \mathrm{cmHg}\right), q / t$ is the volumetric flow rate of gas permeation $\left(\mathrm{cm}^{3}(\mathrm{STP}) / \mathrm{s}\right), P_{1}$ and $P_{2}$ are the pressures $(\mathrm{cmHg})$, and $A$ is the effective membrane area $\left(\mathrm{cm}^{2}\right)$. All permeation measurements were repeated on five different samples, at least three times for each sample.

\section{Results and Discussion}

\subsection{Characteristics of Nano ZIF-8-67 Seeds}

The crystal identities of the ZIF-8, ZIF-67, and ZIF-8-67 (Zn:Co = 0.5:0.5) with metal:ligand:TEA ratios of 1:16:16, which were determined by X-ray diffraction (XRD), are shown in Figure 1 a. The characteristic diffraction peaks of the ZIF-8 occur at $2 \theta=7.43,10.46$, and 12.83, whereas those of the ZIF-67 occur at $2 \theta=7.53,10.56$, and 12.91 , suggesting a sodalite structure. The above results show that the characteristic diffraction peaks of the ZIF-67 are slightly higher than those of the ZIF-8. However, the peaks of both ZIF-67 and ZIF-8-67 are shifted to the right relative to those of ZIF-8, which can be attributed to the $\mathrm{Co}^{2+}$ ions being smaller than the $\mathrm{Zn}^{2+}$ ions. These results qualitatively support the incorporation of $\mathrm{Co}^{2+}$ ions into the framework [21]. As shown in Figure 1b, $\mathrm{N}_{2}$ adsorption/desorption isotherms of ZIF-8, ZIF-67, and ZIF-8-67 reveal a reversible type I isotherm, characteristic of microporous materials. Table 1 shows that the BET (Brunauer-Emmett-Teller) surface area of hybrid metal ZIF-8-67 (1260.40 $\left.\mathrm{m}^{2} \mathrm{~g}^{-1}\right)$ is much larger than those of both ZIF-8 $\left(1048.33 \mathrm{~m}^{2} \mathrm{~g}^{-1}\right)$ and ZIF-67 $\left(1067.82 \mathrm{~m}^{2} \mathrm{~g}^{-1}\right)$. The result can be attributed to the $\mathrm{Co}^{2+}$ ions being smaller than the $\mathrm{Zn}^{2+}$ and $\mathrm{Co}^{2+}$ ions in the structure of ZIF-8, which creates a larger specific surface area. For this study, a large specific surface area was necessary, as this results in effectively achieving $\mathrm{H}_{2} / \mathrm{CO}_{2}$ gas separation; due to the resultant crystallization of thin film materials, this is one of the most important properties. The thin film was therefore designed to adapt the secondary growth method when the first layer was seeding, during which the powder with a larger specific surface area was exceptionally conducive to the growth of seeds. This was beneficial to the crystallization of the thin film structure.
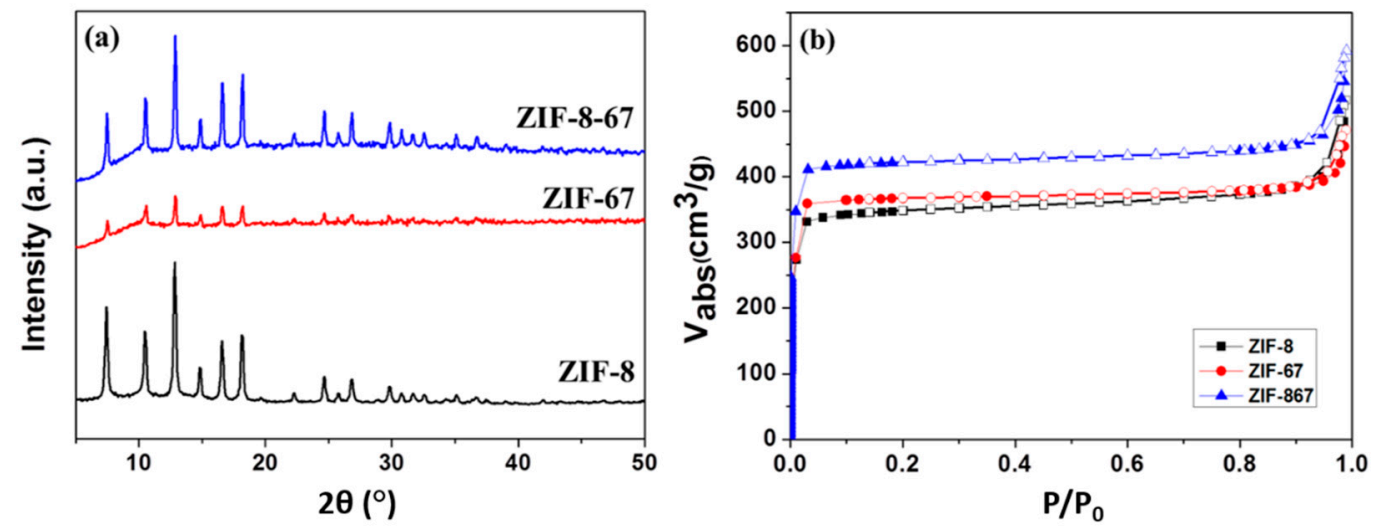

Figure 1. (a) XRD patterns of ZIF-8, ZIF-67, and ZIF-8-67 samples; (b) comparison of $\mathrm{N}_{2}$ adsorption/ desorption isotherms of ZIF-8, ZIF-67, and ZIF-8-67 samples. 
Table 1. Zeolitic imidazolate framework (ZIF) porosimetry data.

\begin{tabular}{ccc}
\hline Material & $\begin{array}{c}\text { BET Surface Area } \\
\left(\mathbf{m}^{\mathbf{2}} \mathbf{g}^{-\mathbf{1}}\right)\end{array}$ & $\begin{array}{c}\text { Micropore Volume } \\
\left(\mathbf{c m}^{\mathbf{3}} \mathbf{g}^{-\mathbf{1}}\right)\end{array}$ \\
\hline ZIF-8 & 1048.33 & 0.485 \\
ZIF-67 & 1067.82 & 0.542 \\
ZIF-8-67 & 1260.40 & 0.616 \\
\hline
\end{tabular}

From the analysis of the SEM images, the ZIF-8 particles were found to have an average diameter of $119 \pm 20 \mathrm{~nm}$ (Figure 2), and the ZIF-67 particles to have an average diameter of $98 \pm 25 \mathrm{~nm}$ (Figure 2). The morphology of the ZIF-8 particles was a polyhedral shape. The ZIF-67 particles resembled the ZIF-8 grown in methanol for $1 \mathrm{~h}$, with a ball shape but with non-uniform size distribution. Similarly, the material ZIF-8-67 displayed a polyhedral morphology. This result may be related to the strength of the crystals, which is consistent with the XRD pattern. Typical TGA curves for all three samples are shown in Figure 3, and they all display three weight-loss stages. The first weight-loss stage between room temperature and $200{ }^{\circ} \mathrm{C}$ occurs due to occluded solvent and water. The second weight-loss stage of ZIF-67 starts at $200^{\circ} \mathrm{C}$ and decreases at $475^{\circ} \mathrm{C}$, whereas ZIF-8-67 and ZIF-8 start to decrease at higher temperatures, up to 520 and $575{ }^{\circ} \mathrm{C}$, respectively. In the third weight-loss stage, the decomposition of organic linkers in the framework caused theatric weight loss. TGA analysis shows that ZIF-8-67 is not as stable as ZIF-8, but is more stable than ZIF-67.
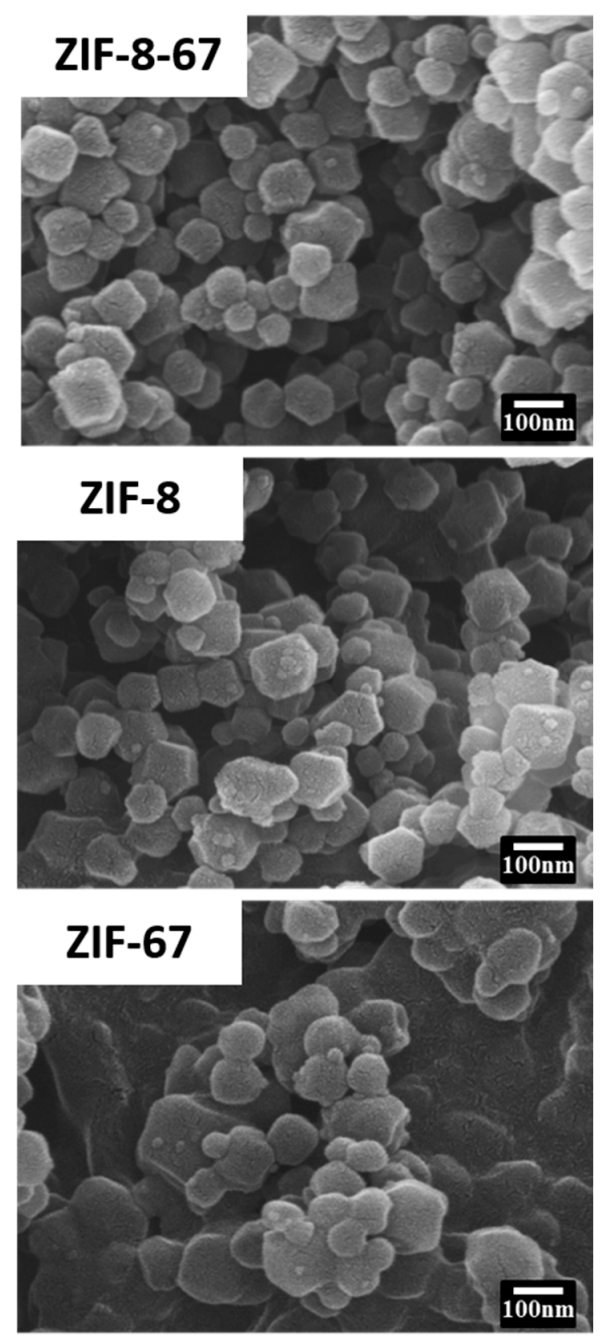

Figure 2. SEM images of ZIF-8, ZIF-67, and ZIF-8-67. 


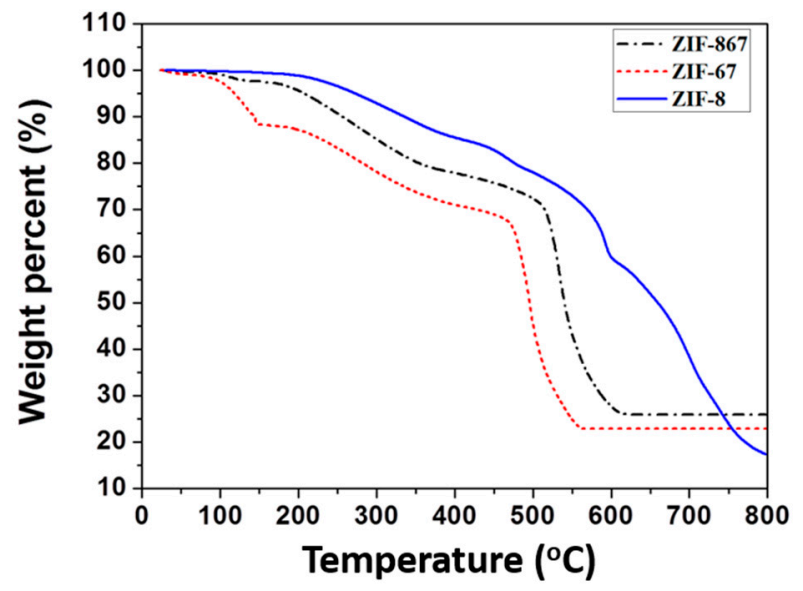

Figure 3. TGA curves of metal: ligand: TEA ratios of 1:16:16 for ZIF-8, ZIF-67, and ZIF-8-67 $(\mathrm{Zn}: \mathrm{Co}=0.5: 0.5)$.

\subsection{Characterization of ZIF-8-67 Membrane}

\subsubsection{Membrane Characterization and Effect of Sodium Formate}

Figure 4a shows the X-ray diffraction patterns of the ZIF-8-67 membrane with different ratios of $\left(\mathrm{Co}^{2+}\right) /\left(\mathrm{Zn}^{2+}\right)+\left(\mathrm{Co}^{2+}\right)$, and illustrates that ZIF-8 was the only crystalline phase present in all samples, with characteristic diffraction peaks around $2 \theta=7,10$, and 13, which correspond to the basal planes of (110), (200), and (211), respectively. These patterns of the membranes ZIF-8, Co26-ZIF-8, Co44-ZIF-8, and Co61-ZIF-8 indicate a well-developed crystalline structure that was indexed as the face-centered hexagonal unit cell. The XRD patterns of the Co26-ZIF-8 membrane exhibited a sharply increased relative intensity of the (200) reflection, in relation to other sample reflections, which indicated an optimal crystal orientation of the (100) planes parallel.
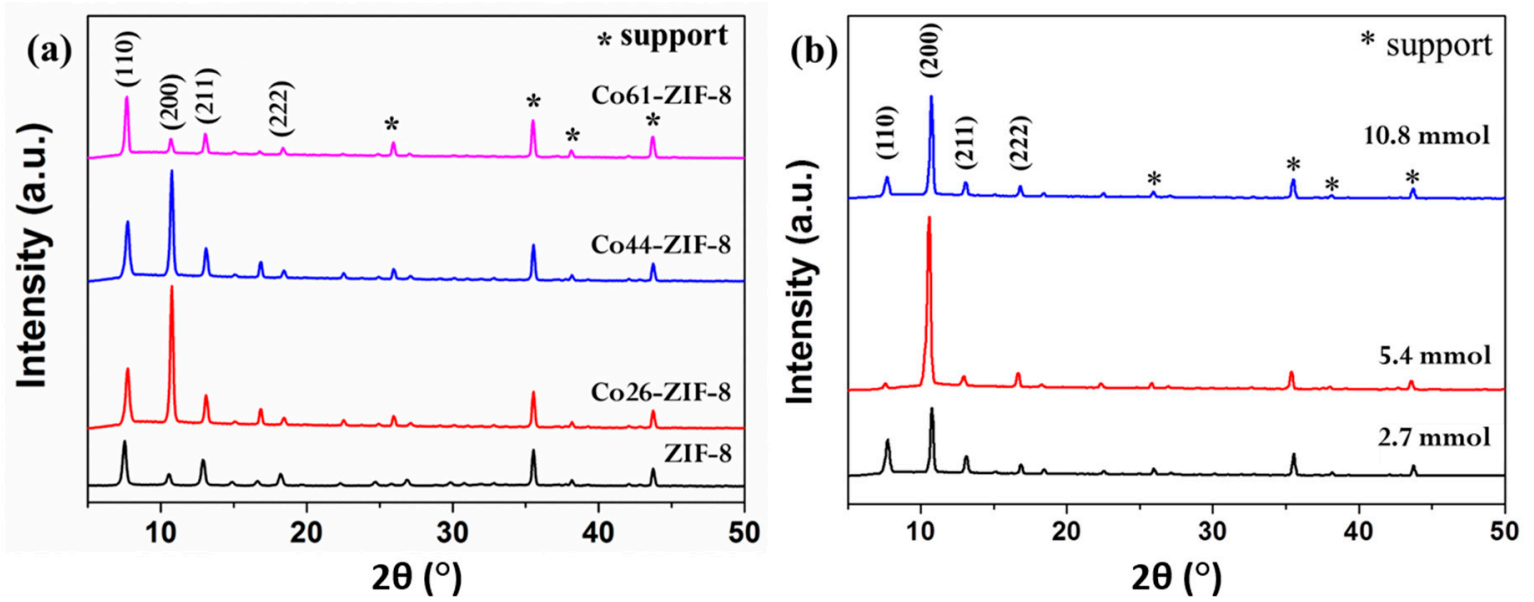

Figure 4. XRD patterns of ZIF-8-67 membrane: (a) with different Co content and (b) structural evolution of the Co44-ZIF-8 membrane with different SF concentrations $\left(2.7,5.4\right.$, and $10.8 \mathrm{mmol}$ at $100{ }^{\circ} \mathrm{C}$ for $2 \mathrm{~h}$ ).

As the Co content increased from Co26 to Co61, the relative intensity of (200) reflection weakened, indicating that the additional Co content affected the adjustment of the deprotonation and nucleation rates. However, this indicates that although the $\mathrm{Co}^{2+}$ ion is smaller than $\mathrm{Zn}^{2+}$ ion, only a limited amount of Co can be associated with structural development into a stoichiometric ZIF as the Co is incorporated into the ZIF-8 framework. Additionally, Co, such as Co61-ZIF-8, would affect the oriented growth. As shown in Figure 4b, the XRD patterns for all Co44-ZIF-8 membranes exhibit a highly 
crystalline pure-phase ZIF-8-67 structure, but the ZIF-8-67 with SF of 5.4 mmol exhibits a more vigorous intensity of the (200) reflection.

According to a previous study [22], ZIF crystals are nucleated on support surfaces, and sodium formate can act as a deprotonator, resulting in uniform and stable growth of crystals in all directions, thus producing a continuous well-symbiotic crystal. When the SF was increased from 2.7 to 5.4 , it likely caused ZIF-8-67 to become fully deprotonated, due to the increase in $\mathrm{pH}$ value, and the solution remained transparent under atmospheric conditions. However, when the $10.8 \mathrm{mmol}$ SF was used, the solution became blurred within $10 \mathrm{~min}$. These observations clearly indicated that more deprotonated $\mathrm{mIM}$ ions could be coordinated with metal ions as $\mathrm{pH}$ concentration increased. As a result, the nucleation rate increased, decreasing crystal growth on the membrane surface. Consequently, the ZIF-8-67 to which $10.8 \mathrm{mmol}$ SF was added displayed a lower (200) reflection.

SEM images of the synthesized membranes with SF content from 2.7 to $10.8 \mathrm{mmol}$ are shown in Figure 5. The top views of the morphology of the grains synthesized from $5.4 \mathrm{mmol}$ are more uniform than those synthesized from $2.7 \mathrm{mmol}$ of SF, with grain size also increasing to $10 \mu \mathrm{m}$ with increasing SF content (Figure $5 \mathrm{a}, \mathrm{c}$ ), indicating that the membrane was fully deprotonated in the $5.4 \mathrm{mmol}$ membrane. The cross-sectional images in Figure 5b,d reveal that the thickness of the membranes synthesized with 2.7 and $5.4 \mathrm{mmol}$ significantly increased from $5 \mu \mathrm{m}$ to $22 \mu \mathrm{m}$, and displayed a compact structure with oriented intergrown grains. They also provide evidence that when there is enough SF, the mIM can be deprotonated, but still grow on the membrane surface to fabricate a thicker membrane of $\sim 22 \mu \mathrm{m}$.

In contrast, when increasing the SF content to $10.8 \mathrm{mmol}$, a non-uniform grain morphology was observed, and the crystal size decreased significantly from 10 to around $5 \mu \mathrm{m}$, as shown in Figure 5e. The cross-sectional view of the membrane demonstrates a reduced thickness from 22 to $10 \mu \mathrm{m}$. This result suggests that the nucleation and crystal growth rates that control thickness are strongly influenced by the concentration of SF in the second growth solution.

\subsubsection{Effect of Ligand}

Figure 6a shows the X-ray diffraction patterns of the hybrid metal ZIF-8-67 membrane with different ratios of $\left(\mathrm{Co}^{2+}\right) /\left(\mathrm{Zn}^{2+}\right)+\left(\mathrm{Co}^{2+}\right)$ synthesized from 2, 4, 8, and $16 \mathrm{mmol}$ 2-methylimidazole $(\mathrm{mIM})$. The results showed that the whole crystal phase was the same as that of the ZIF- 8 membrane, and no other crystal phase was derived. We noted that with the addition of less than $4 \mathrm{mmol}$ of $\mathrm{mIM}$, almost all characteristic diffraction peaks of ZIF-8-67 disappeared, and the synthesized materials became amorphous. Conversely, the membrane with more than $2 \mathrm{mmol}$ of $\mathrm{mIM}$ added had diffraction patterns identical to those of the ZIF-8 membrane, and a relatively strong intensity of the (200) reflection appeared in the Co44-ZIF-8 membrane with $4 \mathrm{mmol} \mathrm{mIM}$, indicating that the Co44-ZIF-8 crystal surface was fully deprotonated in the $4 \mathrm{mmol} \mathrm{mIM}$. However, a further increase in the $\mathrm{mIM}$ proportion caused a decreased intensity of the (200) reflection, due to the phenomenon that more mIM at a fixed SF molar content causes part deprotonation, resulting in the nonuniform growth of the Co44-ZIF-8 membrane.

To further confirm the effect of $\mathrm{Co}^{2+}$ ion coordination in the $\mathrm{mIM}$ on direct synthesis of the membrane in the hybrid metal system, UV-Vis analysis was performed, and the results are shown in Figure 6b. The UV-Vis spectra of the Co44-ZIF-8 secondary growth solution, with different molar ratio ligands and cobalt (II) nitrate hexahydrate dissolved in methanol, indicate the presence of $\mathrm{Co}^{2+}$ ions, as well as their tetrahedral coordination mode in the Co44-ZIF-8 structures. We also noted that in comparison to the UV-Vis spectra, the solutions in Figure $6 \mathrm{c}$ show colors from pink, to blue, to violet, corresponding to 2, 4, and $8 \mathrm{mmol}$ ligands containing Co44-ZIF-8 secondary growth solution, which is likely due to a $\mathrm{Co}^{2+}$ coordination shift from octahedral to tetrahedral. In other words, the tetrahedral coordinated $\mathrm{Co}^{2+}$ sites can be promoted by adding $4 \mathrm{mmol}$ ligands to the solution. In a ligand of over $4 \mathrm{mmol}$, the Co44-ZIF-8 secondary growth solution does not further change its color. 

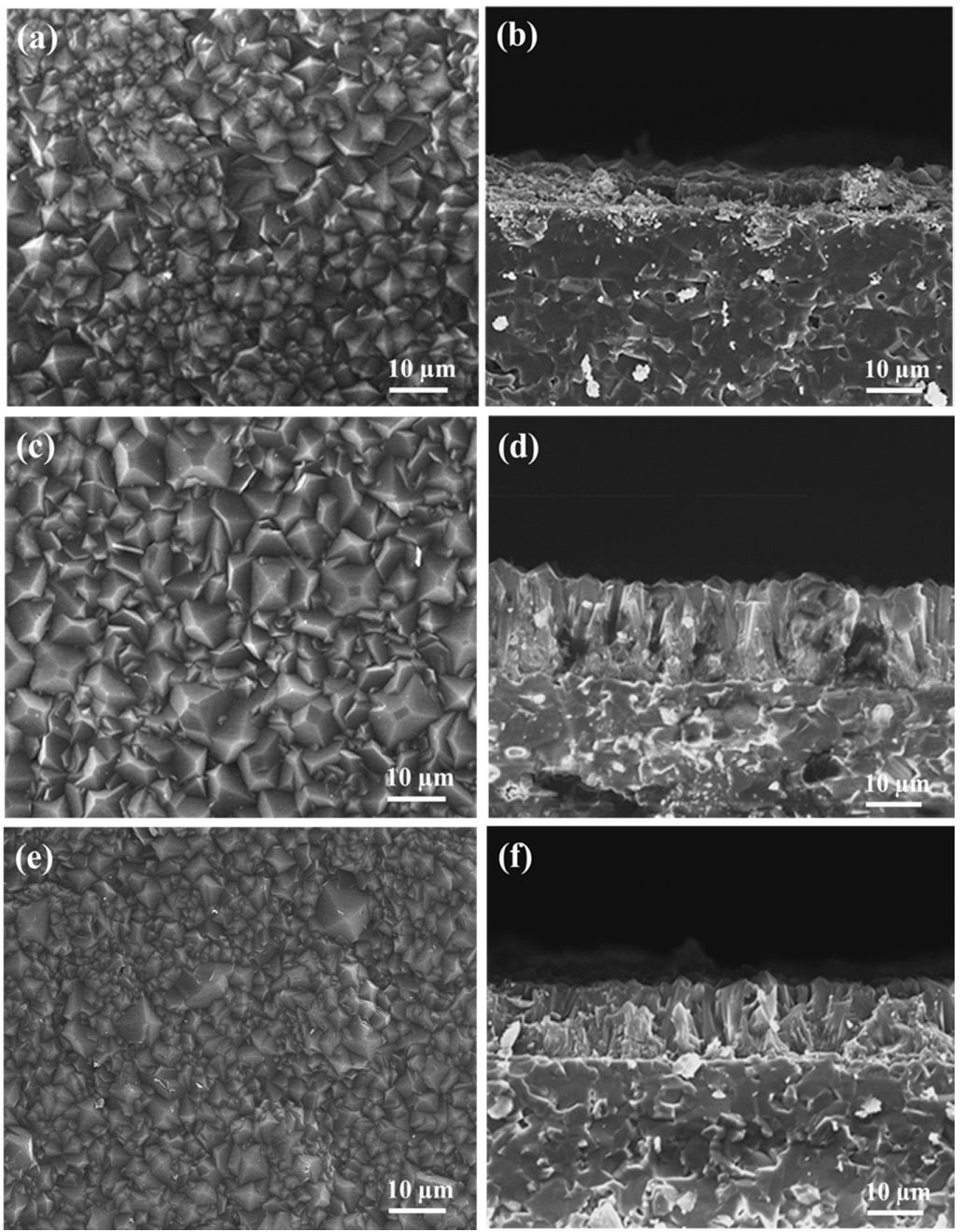

Figure 5. Top-view and cross-section SEM images of the Co44-ZIF-8 membrane with different sodium formate concentrations: $2.7 \mathrm{mmol}(\mathbf{a}, \mathbf{b}), 5.4 \mathrm{mmol}(\mathbf{c}, \mathbf{d})$, and $10.8 \mathrm{mmol}(\mathbf{e}, \mathbf{f})$ at $100{ }^{\circ} \mathrm{C}$ for $2 \mathrm{~h}$.
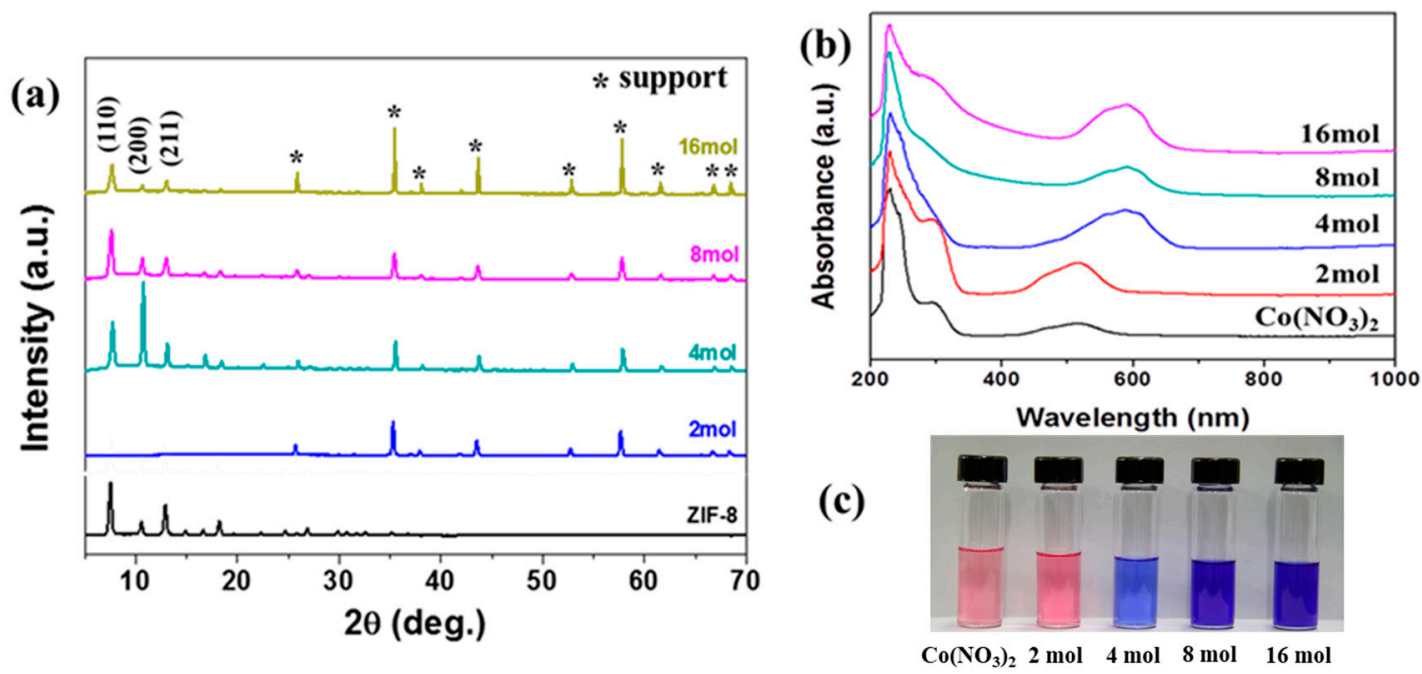

Figure 6. (a) XRD patterns for Co44-ZIF-8 membrane with different mIM concentrations: 2, 4, 8, and 16 $\mathrm{mmol}$ at $100{ }^{\circ} \mathrm{C}$ for $2 \mathrm{~h}$, (b) UV-Vis spectra, and (c) color changes of synthetic solution. 
The SEM top-view microstructures of the hybrid membranes synthesized with different molar concentrations of $\mathrm{mIM}$ are presented in Figure 7. The membrane grown from the solution containing $4 \mathrm{mmol} \mathrm{mIM}$ displayed a continuous and high impact structure, and most grains were highly symbiotic with each other on the $\alpha-\mathrm{Al}_{2} \mathrm{O}_{3}$ substrate. As $\mathrm{mIM}$ increased to $8 \mathrm{mmol}$, a weak intergrown membrane with rhombic dodecahedral shape was observed. With a further increase to $16 \mathrm{mmol}$ $\mathrm{mIM}$, the Co44-ZIF-8 membrane displayed random and discontinuous crystal growth on the surface. This caused more mIM to act as a capping agent, which terminated crystal formation.
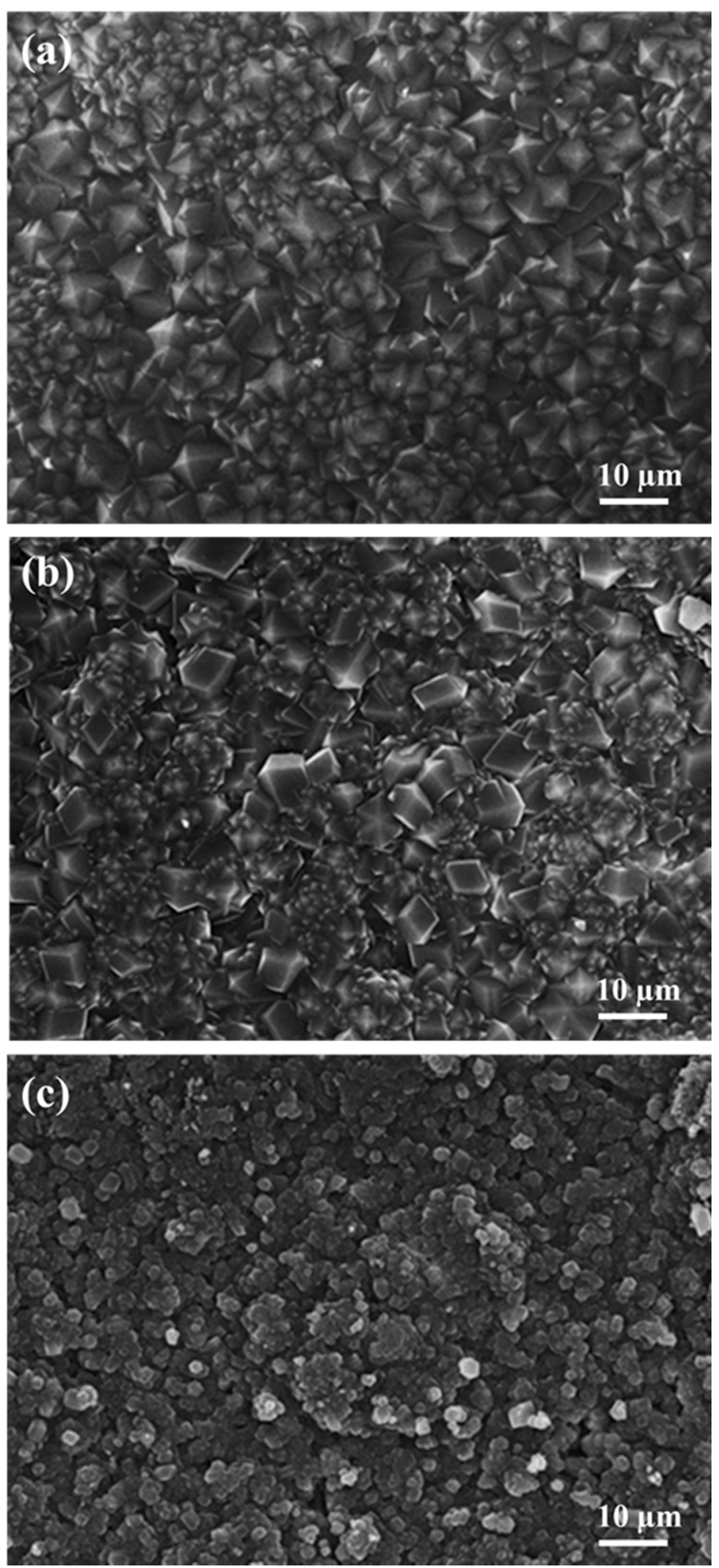

Figure 7. SEM top-view image of Co44-ZIF-8 membrane with different amounts of mIM: (a) 4 mmol, (b) $8 \mathrm{mmol}$, and (c) $16 \mathrm{mmol}$. 


\subsubsection{Effect of Microwave Solvothermal Temperatures}

To better understand the formation of the Co44-ZIF-8 membrane under different reaction temperatures, within microwave solvothermal synthesis, Figure 8 shows the XRD patterns of the Co44-ZIF-8 membrane synthesized at different temperatures. When the reaction temperature is lower than $80^{\circ} \mathrm{C}$, there are no ZIT-8-67 peaks. Such a phenomenon means that the crystal of Co44-ZIF-8 can notfound and form nucleation at a relatively low temperature. A thin amorphous layer appears on the alumina surface, indicating it is not suitable for crystal growth on the support. Once the reaction temperature increases to $100{ }^{\circ} \mathrm{C}$, crystals characteristic of ZIF-8-67 are continuous and adjacent to one another, corresponding to a high-intensity XRD pattern. However, with the temperature further increasing to $150^{\circ} \mathrm{C}$, a discontinuous layer along the bare support is formed, which is consistent with low peak intensities in the XRD pattern. To further understand the effect of the reaction temperature on the nucleation and growth of Co44-ZIF-8, SEM micrographs were recorded.
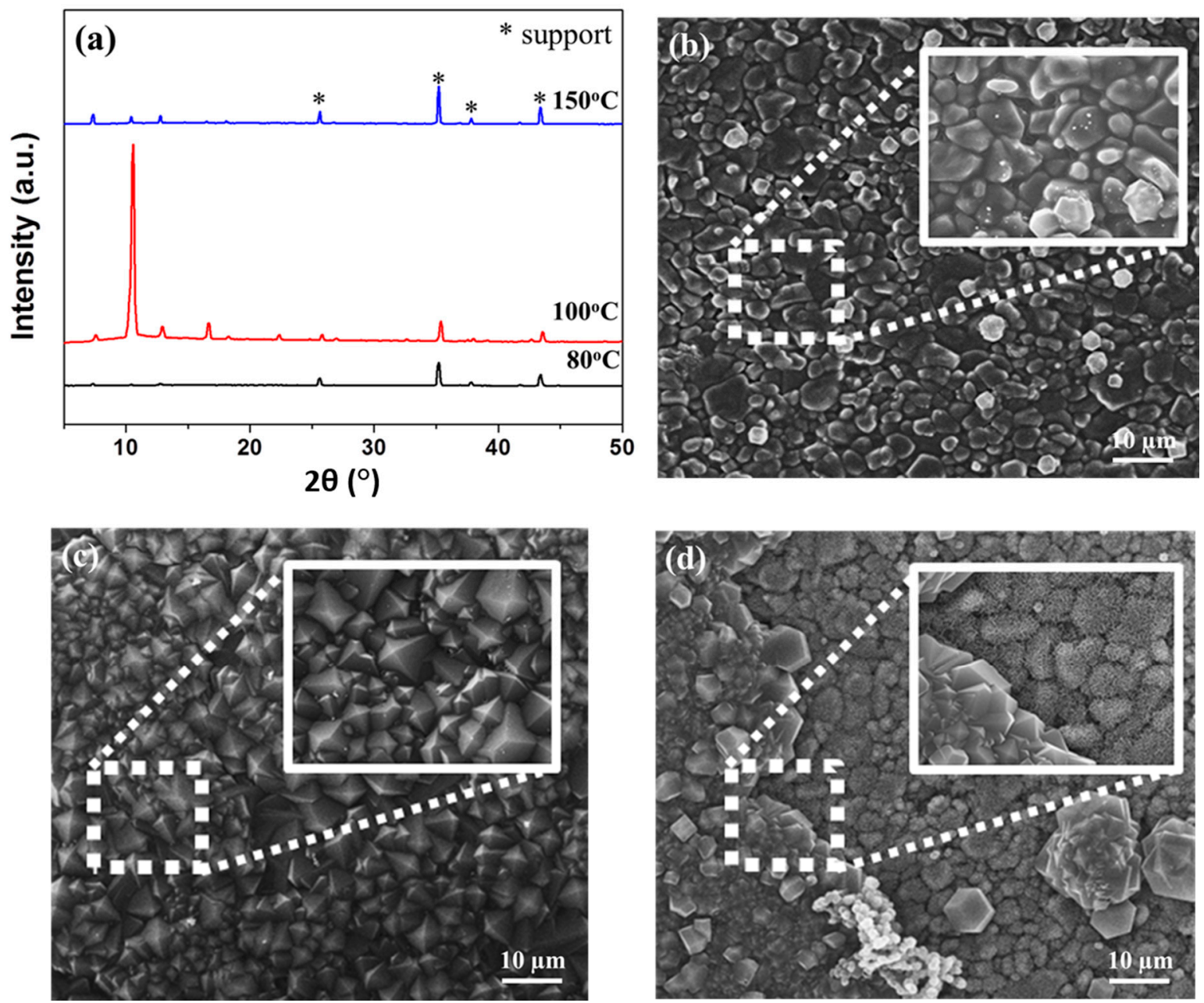

Figure 8. (a) XRD patterns and SEM images of Co44-ZIF-8 membrane prepared with different reaction temperatures: (b) 80, (c) 100, and (d) $150{ }^{\circ} \mathrm{C}$.

\subsection{Gas Permeation Performance of Co44-ZIF-8 Membranes}

The permeation performances of the ZIF-8 and Co44-ZIF-8 membranes were measured using a gas permeation setup. For comparison, we controlled the membrane thickness and crystal orientation of both Co44-ZIF-8 and ZIF-8 membranes so they were identical, with no visible cracks, or other defects observed. Figure 9 shows the gas separation performance of the Co44-ZIF-8 hybrid membrane in terms of different transmembrane pressure drops, i.e., the volumetric flow rates of the single gases 
$\left(\mathrm{H}_{2}, \mathrm{~N}_{2}\right.$, and $\left.\mathrm{CO}_{2}\right)$ through the membrane at room temperature. The single-component gas permeance decreased with increased molecular weights in the order $\mathrm{H}_{2}>\mathrm{N}_{2}>\mathrm{CO}_{2}$. The dominance of gas permeance in diffusion control, but not the molecular sieve control, suggests that the Co44-ZIF- 8 on the membrane surface has more interaction with $\mathrm{CO}_{2}$ than $\mathrm{N}_{2}[23,24]$, which has a significant influence on the permeability through the Co44-ZIF- 8 membrane. This trend is more obvious in the lower pressure drop. Both $\mathrm{CO}_{2}$ and $\mathrm{N}_{2}$ permeance slightly increases with increasing the pressure drop, but $\mathrm{H}_{2}$ permeance decreases with the pressure drop. A further increase in the pressure drop of $\mathrm{H}_{2}$ could enhance the permeation flux, but the increase would not be sufficient to compensate for the higher pressure difference, resulting in decreased permeability. Figure $9 \mathrm{~b}$ shows that the gas permeance selectivity $(\alpha)$ decreased in $\alpha \mathrm{H}_{2} / \mathrm{CO}_{2}$ from 12.4 to 9.0 , and in $\alpha \mathrm{H} 2 / \mathrm{N} 2$ from 3.6 to 2.8 , with increasing feed gas pressure.
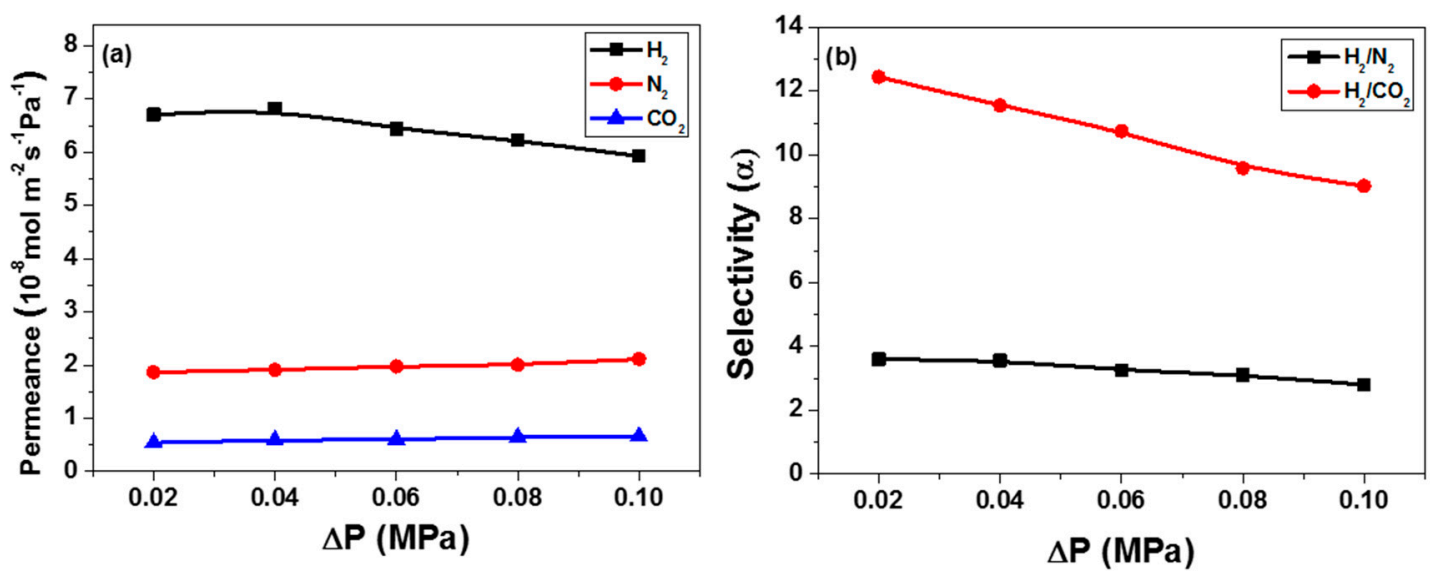

Figure 9. Gas permeance through the Co44-ZIF-8 membrane at different transmembrane pressure drops for (a) single gas permeance and (b) selectivity.

The single component permeability of the gas kinetic diameter test is illustrated in Figure 10. This ZIF-8 membrane has higher $\mathrm{H}_{2}$ and $\mathrm{CO}_{2}$ gas permeance but lower $\mathrm{H}_{2} / \mathrm{CO}_{2}$ selectivity than ZIF-8-67. Notably, our synthesis-oriented ZIF-8 selectivity is lower than in the previous reports, which also noted orientation $[14,15]$. This may be related to the diameter size and character of the $\alpha-\mathrm{Al}_{2} \mathrm{O}_{3}$ disc support. In this study, a larger diameter $(30 \mathrm{~mm}) \alpha-\mathrm{Al}_{2} \mathrm{O}_{3}$ disc was used, which would have a higher chance of producing more defects on the surface, making the membrane density lower. Furthermore, as our seeding ZIF-8 particle size $(\sim 100 \mathrm{~nm})$ was larger than in the literature $(<50 \mathrm{~nm})$, it is also possible that this caused poor stacking in the coating step. A comparison with both Co44-ZIF-8 and ZIF-8 membranes for gas selectivity can be found in Figure 10b. The membrane is composed of Co44-ZIF- 8 with a $\mathrm{H}_{2} / \mathrm{CO}_{2}$ selectivity of nine, which remarkably exceeds the selectivity of the ZIF- 8 membranes. The main reason would be the slightly larger pore volume of the Co44-ZIF- 8 membrane $\left(0.616 \mathrm{~cm}^{3} \mathrm{~g}^{-1}\right)$ compared with the ZIF-8 membrane $\left(0.485 \mathrm{~cm}^{3} \mathrm{~g}^{-1}\right)$. The $\mathrm{Co}^{2+}$ ions incorporated into the ZIF structure are beneficial for the Co44-ZIF- 8 on the membrane surface, and result in more $\mathrm{CO}_{2}$ being adsorbed and diffused into a pore channel.

We can compare this result with those of Jang et al. [25], who reported a maximum $\mathrm{H}_{2} / \mathrm{CO}_{2}$ selectivity of $\sim 7.5 \pm 0.2$ for the membrane, ZIF-8_ $\alpha$. Although the ZIF-8_ $\gamma \alpha$ membrane showed a marked $\mathrm{H}_{2}$ performance, with a maximum $\mathrm{H}_{2} / \mathrm{CO}_{2}$ separation factor of $\sim 9.9 \pm 1.2$, the test temperature was $250{ }^{\circ} \mathrm{C}$.

Previous works demonstrated that MOF membranes' performance for gas separation might be significantly affected by the actual ambient temperature applied. Consequently, the ZIF- 8 and Co44-ZIF-8 membranes was also investigated at different temperatures. Figure 11 shows that when the feed gas is a single component, the permeance values slightly decrease with the increase of the measured temperature. In contrast, $\mathrm{CO}_{2}$ shows a different behavior compared to the ZIF-8 membrane: a decrease 
in gas permeance when the temperature reaches $330 \mathrm{~K}$, then an increase in gas permeance with further increasing temperature. As described by Zhao et al. [26], gas permeability is mainly dependent on temperature, and it can increase or decrease with increasing temperature, which depends entirely on the relative values of activation energy for diffusion, and exothermic adsorption. The probable cause for the $\mathrm{CO}_{2}$ behavior may be the change in the two related properties with the increase in temperature. For the above experimental results, this can be attributed to the Co44-ZIF- 8 membrane that is conducive to enhancing the strong adsorption of $\mathrm{CO}_{2}$ molecules. However, a large quadrupole moment and polarizability facilitated the strong $\mathrm{CO}_{2}$ adsorption [27]. In addition, it must be considered that the rate of diffusion in the channels or pores of the membrane microstructure also has a significant influence on permeability [26,27]. In addition, the sucking behavior of $\mathrm{CO}_{2}$ induces the ideal selectivity to exhibit maximum value as a function of temperature, and this information is beneficial for getting the best-operating conditions for such a membrane. This can be explained by the $\mathrm{Co}^{2+}$ ions in the hybrid metal membrane interacting strongly with $\mathrm{CO}_{2}$, which influences the gas permeance and leads to better $\mathrm{H}_{2} / \mathrm{CO}_{2}$ selectivity.
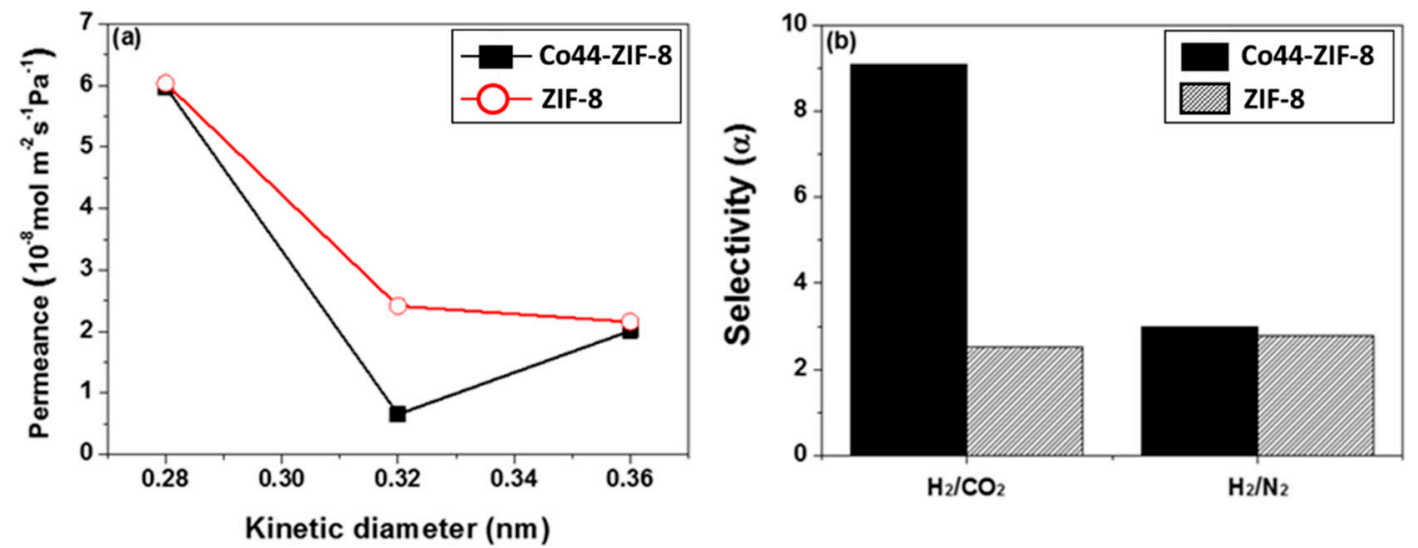

Figure 10. Permeances of single gases for ZIF-8 and Co44-ZIF-8 (a) as a function of the kinetic diameter $\left(\mathrm{H}_{2}: 0.28, \mathrm{CO}_{2}: 0.32\right.$, and $\left.\mathrm{N}_{2}: 0.36 \mathrm{~nm}\right)$ at $25^{\circ} \mathrm{C}$ and $0.1 \mathrm{MPa}$, and $(\mathbf{b})$ the separation factors for $\mathrm{H}_{2} / \mathrm{CO}_{2}$ and $\mathrm{H}_{2} / \mathrm{N}_{2}$.
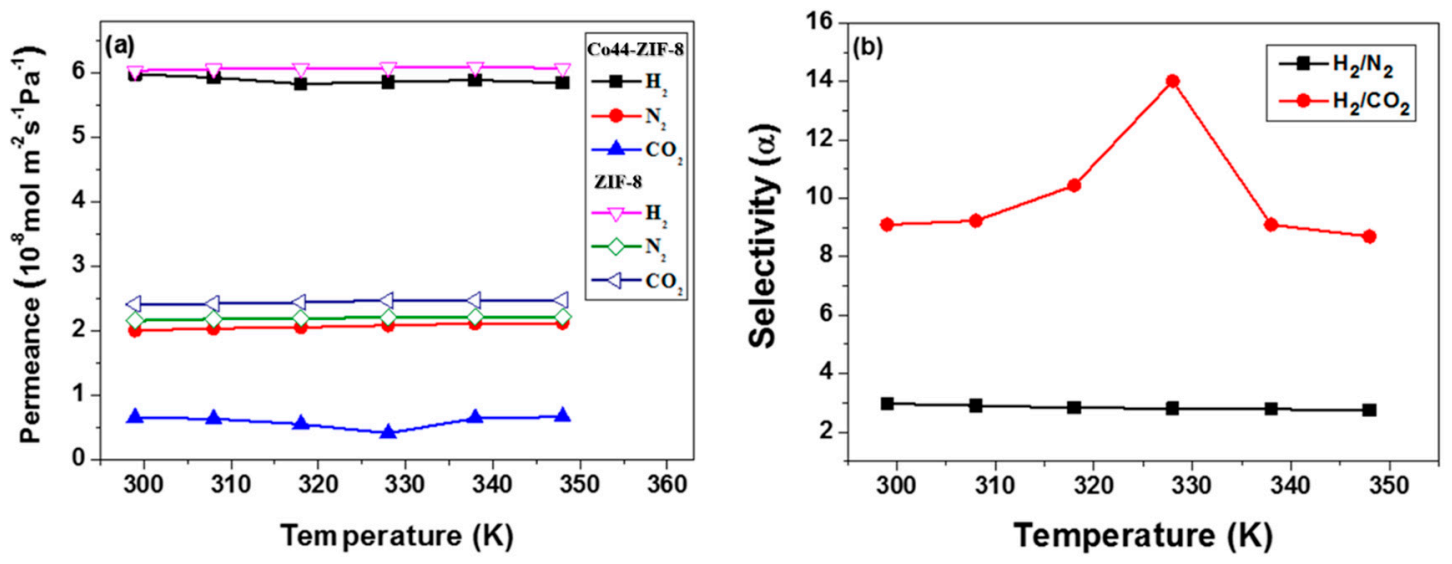

Figure 11. Single component gas permeation of $\mathrm{H}_{2}, \mathrm{~N}_{2}$, and $\mathrm{CO}_{2}$ results for (a) ZIF-8 and Co44-ZIF-8 membranes, and (b) ideal selectivities as functions of temperature.

To prove the stronger interaction between the $\mathrm{CO}_{2}$ and the ZIF-8-67, the powder was collected after secondary growth using a microwave hydrothermal method. The adsorption and desorption of $\mathrm{CO}_{2}$ for ZIF-8 and Co44-ZIF-8 displayed hysteresis loops at $25{ }^{\circ} \mathrm{C}$, and these are shown in 
Figure 12. The maximum $\mathrm{CO}_{2}$ adsorptions of ZIF-8 and Co44-ZIF-8 at 1 atm were 0.88 and $1.07 \mathrm{mmol} \mathrm{g}^{-1}$, respectively. Co44-ZIF-8 contributed more to the $\mathrm{CO}_{2}$ uptake compared to ZIF-8. The interaction of $\mathrm{CO}_{2}$ molecules with the Co44-ZIF- 8 material can be attributed to the fact that the $\mathrm{CO}_{2}$ molecule has a significant quadrupole moment to induce specific interactions with the adsorbents. Therefore, the integrated Co44-ZIF- 8 membrane is thought to have considerable potential in the practical application of hydrogen and carbon dioxide gas separation.

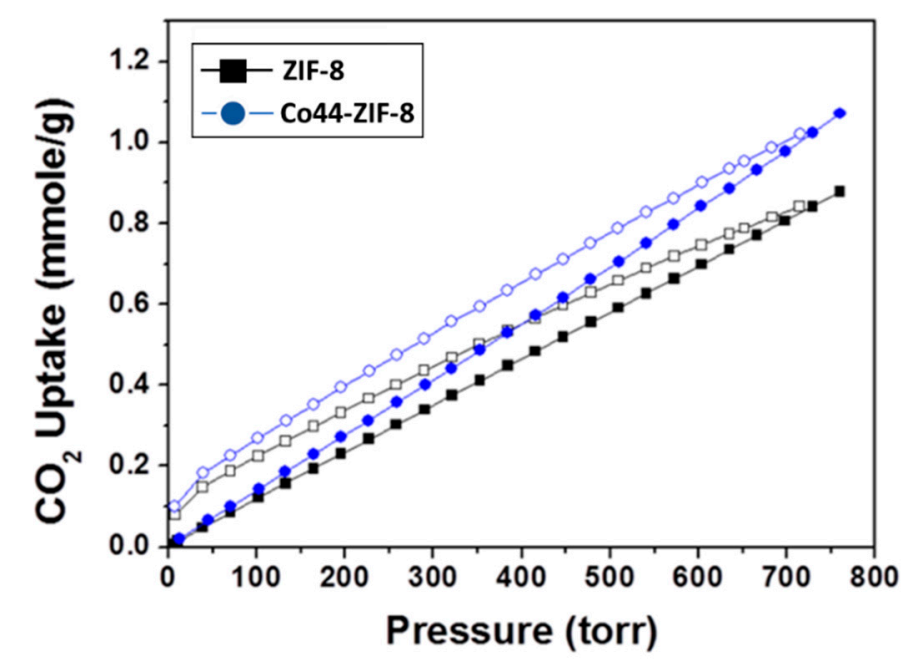

Figure 12. $\mathrm{CO}_{2}$ adsorption-desorption of ZIF-8 and Co44-ZIF-8.

\section{Conclusions}

As a new crystalline, microporous material, metal-organic frameworks have received much interest from membranologists, particularly those engaged in microporous membrane research. For such frameworks to be used as membrane materials, careful consideration should be given to including thermal, hydrothermal, and chemical stability. We synthesized hybrid metal nano ZIF-8-67 crystals to fabricate a novel hybrid metal ZIF-8-67 membrane with the secondary growth method, and using a microwave hydrothermal method. It is the first study to use hybrid metal as a gas separation membrane. In the first part of the study, we used a proficient method for the preparation of ZIF-8-67 crystals with adjusted particle sizes, and in the second part, we successfully developed the hybrid metal ZIF-8-67 membrane on a porous $\alpha$-alumina substrate, using secondary growth synthesis. The membrane not only has a preferred (200) reflection but also exhibits outstanding thermal stability and excellent quality. Single-gas permeation of the hybrid metal ZIF-8-67 membrane demonstrated smaller permeation than the ZIF-8 membrane, but the selectivity was better than the ZIF-8 membrane. The framework with hybrid metal, which contains $\mathrm{Co}^{2+}$ ions, had strong interactions between $\mathrm{CO}_{2}$ and the hybrid metal ZIF-8-67 membrane, which were confirmed to adsorb and desorb $\mathrm{CO}_{2}$ at $298 \mathrm{~K}$. Our study provides a novel idea for the fabrication of hybrid metal ZIF-8-67 membranes, as well as an improvement in $\mathrm{H}_{2} / \mathrm{CO}_{2}$ gas separation performance. The results of our work will help ZIF membrane research, and can hopefully be further applied in industry in the future.

Author Contributions: Conceptualization, Y.-T.L. and P.-H.C.; methodology, Y.-T.L. and P.-H.C.; validation, Y.-T.L. and P.-H.C.; investigation, P.-H.C.; resources, P.-H.C. and C.-H.P.; data curation, Y.-T.L. and P.-H.C.; writing—original draft preparation, Y.-T.L.; writing—review and editing, C.-H.P.; supervision, P.-H.C. and C.-H.P.; project administration, C.-H.P.; funding acquisition, C.-H.P. All authors have read and agreed to the published version of the manuscript.

Funding: This research received no funding.

Conflicts of Interest: The authors declare no conflict of interest. 


\section{References}

1. Yaghi, O.M.; O’Keeffe, M.; Ockwig, N.W.; Chae, H.K.; Eddaoudi, M.; Kim, J. Reticular synthesis and the design of new materials. Nature 2003, 423, 705-714. [CrossRef]

2. Park, K.S.; Zheng, N.; Côté, A.P.; Choi, J.Y.; Huang, R.D.; Uribe-Romo, F.J.; Chae, H.K.; O’Keeffe, M.; Yaghi, O.M. Exceptional chemical and thermal stability of zeolitic imidazolate frameworks. Proc. Natl. Acad. Sci. USA 2006, 103, 10186-10191. [CrossRef]

3. Hayashi, H.; Côté, A.P.; Furukawa, H.; O’Keeffe, M.; Yaghi, O.M. Zeolite A imidazolate frameworks. Nat. Mater. 2007, 6, 501-506. [CrossRef] [PubMed]

4. Banerjee, R.; Phan, A.; Wang, B.; Knobler, C.; Furukawa, H.; O’Keeffe, M.; Yaghi, O.M. High-throughput synthesis of zeolitic imidazolate frameworks and application to $\mathrm{CO}_{2}$ capture. Science 2008, 319, 939-943. [CrossRef] [PubMed]

5. Brunelli, N.A.; Didas, S.A.; Venkatasubbaiah, K.; Jones, C.W. Tuning cooperativity by controlling the linker length of silica-supported amines in catalysis and $\mathrm{CO}_{2}$ capture. J. Am. Chem. Soc. 2012, 134, 13950-13953. [CrossRef] [PubMed]

6. Hu, Y.X.; Dong, X.L.; Nan, J.P.; Jin, W.Q.; Ren, X.M.; Xu, N.P.; Lee, Y.M. Metal-organic framework membranes fabricated via reactive seeding. Chem. Commun. 2011, 47, 737-739. [CrossRef]

7. Dong, X.L.; Huang, K.; Liu, S.; Ren, R.; Jin, W.; Lin, Y.S. Synthesis of zeolitic imidazolate framework-78 molecular-sieve membrane: Defect formation and elimination. J. Mater. Chem. 2012, 22, 19222-19227. [CrossRef]

8. Bux, H.; Liang, F.Y.; Li, Y.S.; Cravillon, J.; Wiebcke, M.; Caro, J. Zeolitic imidazolate framework membrane with molecular sieving properties by microwaveassisted solvothermal synthesis. J. Am. Chem. Soc. 2009, 131, 16000-16001. [CrossRef] [PubMed]

9. Pan, Y.C.; Wang, B.; Lai, Z.P. Synthesis of ceramic hollow fiber supported zeolitic imidazolate framework-8 (ZIF-8) membranes with high hydrogen permeability. J. Membr. Sci. 2012, 421-422, 292-298. [CrossRef]

10. Pimentel, B.R.; Parulkar, A.; Zhou, E.K.; Brunelli, N.A.; Lively, R.P. Zeolitic imidazolate frameworks: Next-generation materials for energy-efficient gas separations. ChemSusChem 2014, 7, 3202-3240. [CrossRef]

11. Arami-Niya, A.; Birkett, G.; Zhu, Z.; Rufford, T.E. Gate opening effect of zeolitic imidazolate framework ZIF-7 for adsorption of $\mathrm{CH}_{4}$ and $\mathrm{CO}_{2}$ from $\mathrm{N}_{2}$. J. Mater. Chem. A 2017, 5, 21389-21399. [CrossRef]

12. Karger, J.; Ruthven, D.M. Diffusion in nanoporous materials: Fundamental principles, insights and challenges. New J. Chem. 2016, 40, 4027-4048. [CrossRef]

13. Avci, C.; Ariñez-Soriano, J.; Carné-Sánchez, A.; Guillerm, C.; Carbonell, C.; Imaz, I.; Maspoch, D. Post-synthetic anisotropic wet-chemical etching of colloidal sodalite ZIF crystals. Angew. Chem. Int. Ed. 2015, 54, 14417-14421. [CrossRef]

14. Li, Q.; Guo, J.N.; Zhu, H.; Yan, F. Space-confined synthesis of ZIF-67 nanoparticles in hollow carbon nanospheres for $\mathrm{CO}_{2}$ adsorption. Small 2019, 15, 1804874. [CrossRef]

15. Zhou, Z.M.; Wu, C.; Zhang, B.Q. ZIF-67 membranes synthesized on $\alpha-\mathrm{Al}_{2} \mathrm{O}_{3}$-plate-supported cobalt nanosheets with amine modification for enhanced $\mathrm{H}_{2} / \mathrm{CO}_{2}$ permselectivity. Ind. Eng. Chem. Res. 2020, 59, 3182-3188. [CrossRef]

16. Thompson, J.A.; Blad, C.R.; Brunelli, N.A.; Lydon, M.E.; Lively, R.P.; Jones, C.W.; Nair, S. Hybrid zeolitic imidazolate frameworks: Controlling framework porosity and functionality by mixed-linker synthesis. Chem. Mater. 2012, 24, 1930-1936. [CrossRef]

17. Kahr, J.; Mowat, J.P.S.; Slawin, A.M.Z.; Morris, R.E.; Fairen-Jimenez, D.; Wright, P.A. Synthetic control of framework zinc purinate crystallisation and properties of a large pore, decorated, mixed-linker RHO-type ZIF. Chem. Commun. 2012, 48, 6690-6692. [CrossRef] [PubMed]

18. Botas, J.A.; Calleja, G.; Sánchez-Sánchez, M.; Orcajo, M.G. Cobalt doping of the MOF-5 framework and its effect on gas-adsorption properties. Langmuir 2010, 26, 5300-5303. [CrossRef]

19. Zhang, X.R.; Zhang, T.; Wang, Y.H.; Li, J.P.; Liu, C.C.; Li, N.W.; Liao, J.Y. Mixed-matrix membranes based on $\mathrm{Zn}$ /Ni-ZIF-8-PEBA for high performance $\mathrm{CO}_{2}$ separation. J. Membr. Sci. 2018, 560, 38-46. [CrossRef]

20. Fan, Y.F.; Huiya Yu, H.Y.; Xu, S.; Shen, Q.C.; Ye, H.M.; Li, N.W. Zn(II)-modified imidazole containing polyimide/ZIF-8 mixed matrix membranes for gas separations. J. Membr. Sci. 2020, 597, 117775-117785. [CrossRef] 
21. McCarthy, M.C.; Varela-Guerrero, V.; Barnett, G.V.; Jeong, H.-K. Synthesis of zeolitic imidazolate framework films and membranes with controlled microstructures. Langmuir 2010, 26, 14636-14641. [CrossRef]

22. Liu, Y.; Hu, E.; Khan, E.A.; Lai, Z. Synthesis and characterization of ZIF-69 membranes and separation for $\mathrm{CO}_{2} / \mathrm{CO}$ mixture. J. Membr. Sci. 2010, 353, 36-40. [CrossRef]

23. Zhang, Z.J.; Xian, S.K.; Xia, Q.B.; Wang, H.H.; Zhong, L.; Li, J. Enhancement of $\mathrm{CO}_{2}$ Adsorption and $\mathrm{CO}_{2} / \mathrm{N}_{2}$ Selectivity on ZIF-8 via Postsynthetic Modification. AIChE J. 2013, 59, 2195-2206. [CrossRef]

24. Liu, B.; Smit, B. Molecular Simulation Studies of Separation of $\mathrm{CO}_{2} / \mathrm{N}_{2}, \mathrm{CO}_{2} / \mathrm{CH}_{4}$, and $\mathrm{CH}_{4} / \mathrm{N}_{2}$ by ZIFs. J. Phys. Chem. C 2010, 114, 8515-8522. [CrossRef]

25. Jang, E.H.; Kim, E.J.; Kim, H.J.; Lee, T.H.; Yeom, H.J.; Kim, Y.K.; Choi, J.K. Formation of ZIF-8 membranes inside porous supports for improving both their $\mathrm{H}_{2} / \mathrm{CO}_{2}$ separation performance and thermal/mechanical stability. J. Membr. Sci. 2017, 540, 430-439. [CrossRef]

26. Xu, X.L.; Zhao, X.X.; Sun, L.B.; Liu, X.Q. Adsorption separation of carbon dioxide, methane, and nitrogen on $\mathrm{Hb}$ and Na-exchanged b-zeolite. J. Nat. Gas Chem. 2008, 17, 391-396. [CrossRef]

27. Zhao, Z.X.; Ma, X.L.; Li, Z.; Lin, Y.S. Synthesis, characterization and gas transport properties of MOF-5 membranes. J. Membr. Sci. 2011, 382, 82-90. [CrossRef]

Publisher's Note: MDPI stays neutral with regard to jurisdictional claims in published maps and institutional affiliations.

(C) 2020 by the authors. Licensee MDPI, Basel, Switzerland. This article is an open access article distributed under the terms and conditions of the Creative Commons Attribution (CC BY) license (http://creativecommons.org/licenses/by/4.0/). 